\title{
Remnant creep based visco-elastic model for concrete creep analysis
}

1 Albert K. H. Kwan PhD, FHKIE, MICE, CEng, RPE Professor, Department of Civil Engineering, The University of Hong Kong, Hong Kong, China
2 Pui Lam Ng PhD, MHKIE, MICE, CEng, RPE Honorary Research Associate, Department of Civil Engineering, The University of Hong Kong, Hong Kong, China
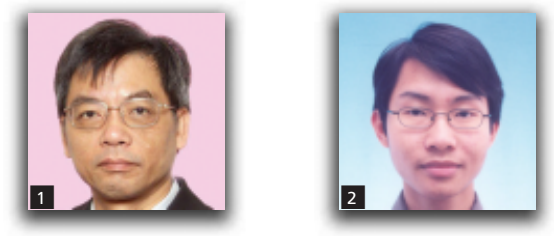

Creep of concrete could cause adverse stress redistributions and excessive deformations. Its structural effects can be assessed by conducting time-step analysis using finite-element methods with time-integration formulation, in which the creep strain at any time is determined as the cumulative creep responses to stress increments in previous time steps. This process entails memorisation of the stress histories of all the concrete elements, leading to prohibitive demands of computer memory and time, especially for large and complex structures. To avoid having to memorise the stress histories, a remnant creep based visco-elastic model is developed, whereby the remnant creep strains are employed to evaluate the incremental creep strains. This model circumvents the need for memorising the stress histories and possesses a great flexibility in fitting with codified creep formulas. Numerical examples are presented to demonstrate the general applicability of the proposed model.

\section{Notation}

$c_{\mathrm{V}} \quad$ weighting coefficient

$E_{\mathrm{c}} \quad$ elastic modulus of concrete

$m$ number of repeated units

$t$ time

$t_{0.5} \quad$ creep half-time

$t_{\mathrm{s}} \quad$ time at drying starts

$\varepsilon_{\mathrm{cc}} \quad$ creep strain

$\varepsilon_{\mathrm{ce}} \quad$ instant elastic strain

$\varepsilon_{\mathrm{rc}} \quad$ remnant creep strain

$\varepsilon_{\mathrm{v}} \quad$ remnant creep strain in repeated unit

$\sigma_{\mathrm{c}} \quad$ applied stress

$\tau \quad$ time

$\phi \quad$ creep coefficient

$\phi_{0} \quad$ notional creep coefficient

$\phi_{\mathrm{r}} \quad$ remnant creep coefficient

$\omega_{\mathrm{v}} \quad$ characteristic rate

\section{Introduction}

The creep of concrete is the gradual increase in deformation of concrete under sustained load (Neville, 2011). As time goes by, it could cause adverse stress redistributions and excessive deformations. In practice, its structural effects are manifold. First, it could cause loss of prestress in prestressed concrete structures, which often have to be overstressed initially in order to compensate for such loss. Second, it could aggravate the deflections of flexural members, leading to the concern of possible excessive deflections of long-span beams and bridges. Third, it could augment the differential axial shortening of the vertical members in tall buildings, which might induce large shear forces and bending moments in the horizontal members connected to the vertical members (Kwan et al., 2003).

The structural effects of the creep of concrete can be assessed by conducting time-step analysis, taking into account the loading history of the structure and the time-dependent properties of the concrete. For assessing the long-term creep effects, only the sustained loads in the loading history need to be considered. However, there are many time-dependent properties of concrete to be considered, such as the gain in elastic modulus during strength development, autogenous shrinkage, drying shrinkage, early thermal expansion and contraction owing to heat generation of curing concrete, thermal expansion and contraction due to environmental temperature changes and, of course, creep (Ghali et al., 2012; Gilbert and Ranzi, 2011).

Among the above time-dependent properties of concrete, the shrinkage and thermal expansion/contraction will produce movement of the structure, which if restrained, will induce internal loads. Such internal loads induced by movement restraints may cause cracking and even failure of the structure, and therefore also need to be considered. Nevertheless, the creep of concrete would generally help to alleviate the internal loads induced by movement restraints (Kwan and Ng, 2009). Hence, the creep of 
concrete is not always detrimental to structural health but can sometimes be beneficial. All in all, time-dependent movements, internal loads induced by restraints and creep interact with each other and thus should not be considered separately. An integrated analysis considering all these factors is required.

Time-dependent shrinkage, thermal and creep movements take place not only after completion of construction but also during construction, especially when the construction period is long or the construction is carried out in stages. These could significantly affect the initial stresses (also called locked-in stresses) in the structure at the time of completion. The movements during construction could be detrimental or beneficial but in any case must be taken into account in the structural analysis and design. Their immediate and long-term effects are highly dependent on the construction method and sequence. In fact, quite often, preloading or prestressing are applied and/or the construction sequence is strategically planned to purposely accelerate or delay certain parts of the works in order to minimise the detrimental effects and maximise the beneficial effects (Kwan and Ng, 2009). Such active or passive construction measures aiming to cater for the movements during construction fall within the scope of construction control.

The importance of construction control can be seen from the following examples. During the construction of cable-stayed bridges by launching the deck segments in stages, the timedependent deck movements need to be analysed and monitored on-site so that the cable forces can be adjusted to achieve perfect match upon closure of the deck segments (Guan, 2000; Han and Yan, 2003). Likewise, during the construction of multi-storey buildings, the shrinkage of the floors would cause deformation of the vertical members and induce tensile stresses in the floors, which are often large enough to cause cracking. Such detrimental effects can be alleviated by the provision of late-cast strips, which are not cast until substantial shrinkage of the other parts of the floors has taken place (Kim and Cho, 2004, 2005; Kwan et al., 2002; Kwan and $\mathrm{Ng}$, 2009). However, there are very few design guides or computer programs that could help to analyse the effects of time-dependent movements and assist the design of construction control measures. For many years, there has been constant demand from the industry for such design aids.

Time-step analysis of the structural effects of time-dependent movements is not an easy task. In most cases, it is necessary to employ the finite-element method because of the following reasons. First, modern structures are generally far too complicated to be analysed by simple calculations. Second, since different parts of the structure may have different time-dependent properties, the structure has to be divided into many small elements for analysis. Third, since all the time-dependent effects have to be considered at the same time so as to allow for their complex interactions, each small element needs to be analysed at each time step for its strains under external and internal loads, and shrinkage, thermal and creep strains. Fourth, the movement restraints, which are generally neither perfectly rigid nor completely free, have to be modelled as structural elements as well. Fifth, different parts of the structure may be constructed at different times (or, in other words, may have different birthdays) and thus have to be modelled as separate structural elements.

In conducting finite-element analysis of time-dependent problems, the whole time period is discretised into a series of time steps, the structure is analysed at each time step for the stresses, strains and movements, and step-by-step time integration is performed for each concrete element to evaluate the cumulative effects of creep (Anderson, 1982; Ghali et al., 2012). In theory, any appropriate shrinkage and creep models of concrete can be adopted for the analysis. Regardless of the shrinkage and creep models adopted, the creep strains are generally evaluated as the cumulative creep responses to stress increments in all previous time steps. Hence, for each and every concrete element, the entire stress history needs to be memorised just to evaluate the creep strain at a particular time step. This entails memorisation of the stress outputs of all concrete elements at all time steps. The computer memory and time demands are enormous. This is in fact the major hurdle to the development of time-step finiteelement analysis and practical application of such analysis to real-life engineering problems.

In view of the above, some researchers (Bazant, 1982; Bazant and $\mathrm{Wu}, 1974)$ have chosen to adopt the visco-elastic creep models that do not require step-by-step time integration of creep responses to stress increments in all previous time steps so as to avoid the necessity of memorising the stress histories of all the concrete elements. However, the existing visco-elastic models are generally formulated in such a way that the creep strains are evaluated in terms of the stress rates. This formulation works well if the stresses in the various concrete elements vary as smooth functions of time. If the loads are applied abruptly as discrete time step functions, or if the concrete structure is constructed in stages such that the structural configuration could abruptly change with time, or if the concrete structure cracks, leading to rapid stress redistributions, the stresses in the concrete structure could suddenly change in the form of discrete stress increments and the stress rates at certain moments could become undefined.

Herein, an alternative and more fundamental remnant-creep-based approach using a multi-rheological unit model with the creep strains evaluated in terms of stress increments rather than stress rates is proposed. This approach would circumvent the memorisation of stress histories to reclaim computational efficiency and is applicable even when the stresses could abruptly change in the form of discrete stress increments (in other words, even when the stress rates could become undefined). Preliminary study has revealed that it is feasible, versatile and accurate $(\mathrm{Ng}$ et al., 2007). Furthermore, the rheological parameters of such a remnant-creep-based, multi-rheological unit model for simulating the creep effects in accordance with the various design codes (the creep models stipulated therein are generally in the form of creep 
coefficient-time curves not suitable for numerical analysis using visco-elastic creep models) are evaluated and presented for general applications.

\section{Mechanisms of concrete creep}

Over the years, different mechanisms of concrete creep had been put forward, but the genuine mechanism has remained controversial (ACI, 1992). Two major mechanisms are believed to be dominant (Acker and Ulm, 2001; Neville, 1955, 1958, 2011). The first mechanism is the viscous sliding of calcium-silicate-hydrate (C-S-H) gel particles against each other and across microcracks. Research on the relation between creep and gel density (Neville, 1958; Vandamme and Ulm, 2009) suggested that the gel particles would slide against each other or rearrange themselves to achieve a higher density during creep. Creep tests of cement paste (Beaudoin et al., 2000; Tamtsia et al., 2004; Tamtsia and Beaudoin, 2000) have reaffirmed this mechanism. The second mechanism is the internal movement of adsorbed or intra-crystalline water, which is also known as internal seepage. It is believed to be caused mainly by changes in the hygral equilibrium within the pore structure of concrete (Neville, 1955; Powers, 1968).

When concrete is under a sustained stress, the corresponding stress-dependent strain of concrete comprises two components: an instant elastic strain and a time-dependent creep strain. The elastic strain occurs immediately, whereas the creep strain increases with time at a gradually decreasing rate. For a constant stress $\sigma_{\mathrm{c}}$ applied at time $t_{0}$, the instant elastic strain $\varepsilon_{\mathrm{ce}}\left(t, t_{0}\right)$ and the time-dependent creep strain $\varepsilon_{\mathrm{cc}}\left(t, t_{0}\right)$ at any time $t$ after $t_{0}$ are given respectively by

1. $\varepsilon_{\mathrm{ce}}\left(t, t_{0}\right)=\frac{\sigma_{\mathrm{c}}\left(t_{0}\right)}{E_{\mathrm{c}}\left(t_{0}\right)}$

2. $\varepsilon_{\mathrm{cc}}\left(t, t_{0}\right)=\phi\left(t, t_{0}\right) \varepsilon_{\mathrm{ce}}\left(t, t_{0}\right)$

in which $E_{\mathrm{c}}\left(t_{0}\right)$ is the elastic modulus of concrete at the time of stress application, and $\phi\left(t, t_{0}\right)$ is the creep coefficient describing the time-dependence of creep. Combining Equations 1 and 2, the governing equation of concrete creep is obtained as

3. $\varepsilon_{\mathrm{cc}}\left(t, t_{0}\right)=\phi\left(t, t_{0}\right) \frac{\sigma_{\mathrm{c}}\left(t_{0}\right)}{E_{\mathrm{c}}\left(t_{0}\right)}$

If the applied stress $\sigma_{\mathrm{c}}$ is not constant, the total stress-dependent strain may be evaluated using the principle of superposition, which postulates that the response of concrete to a sum of two stress histories may be obtained as the sum of the individual response to each stress history (McHenry, 1943). By virtue of this principle, the stress history is decomposed into a number of stress increments as in Figure 1 and the elastic strain and creep strain

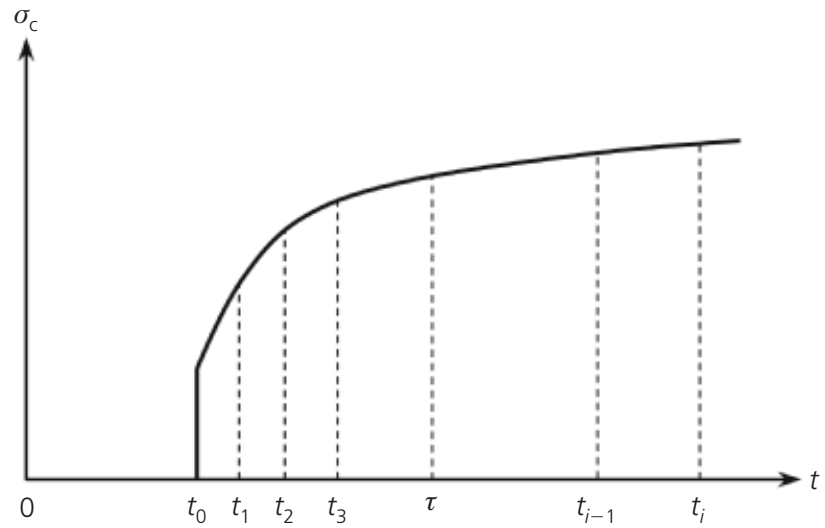

(a)

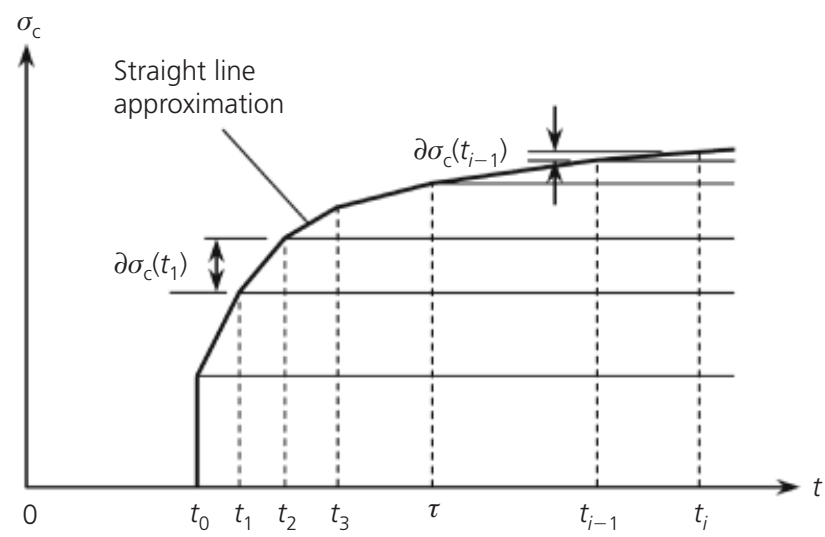

(b)

Figure 1. Decomposition of stress history into stress increments: (a) variation of stress with time; (b) stress increments

caused by a variable stress are evaluated by summing the responses to the stress increments $\partial \sigma_{\mathrm{c}}(\tau)$ each applied at time $\tau$ from $t_{0}$ to $t$ as

4.

$$
\varepsilon_{\mathrm{ce}}\left(t, t_{0}\right)=\frac{\sigma_{\mathrm{c}}\left(t_{0}\right)}{E_{\mathrm{c}}\left(t_{0}\right)}+\int_{\tau=t_{0}}^{t} \frac{\partial \sigma_{\mathrm{c}}(\tau)}{E_{\mathrm{c}}(\tau)}
$$

$$
\varepsilon_{\mathrm{cc}}\left(t, t_{0}\right)=\phi\left(t, t_{0}\right) \frac{\sigma_{\mathrm{c}}\left(t_{0}\right)}{E_{\mathrm{c}}\left(t_{0}\right)}+\int_{\tau=t_{0}}^{t} \phi(t, \tau) \frac{\partial \sigma_{\mathrm{c}}(\tau)}{E_{\mathrm{c}}(\tau)}
$$

In finite-element analysis, the above integrations are performed numerically. When so doing, the stress history of each and every concrete element is required and therefore has to be stored in the computer memory. Generally, the accuracy of the numerical integrations would improve with increasing number of time steps. However, increasing the number of time steps would greatly increase the computer memory needed to store the stress histories 
of the concrete elements and the computer time needed for the analysis. For this reason, when the above time-integration formulation is directly employed in the time-step finite-element analysis, a compromise between numerical accuracy and computational efficiency has to be made.

\section{Visco-elastic modelling of creep}

\subsection{Overview of visco-elastic models}

In general, the time-dependent stress-strain behaviour of a material can be described by the parameters of its constitutive rheological elements. There are three types of basic rheological elements. The first type is an elastic spring and is referred to as Hookean or elastic element. The second type is a viscous damper and is referred to as Newtonian or viscous element. The third type is a plastic body and is referred to as St. Venant or plastic element. Readers may consult general textbooks (Creus, 1986; Neville et al., 1983) for further explanations. By connecting the rheological elements in series and/or in parallel, various rheological models have been developed. If plasticity is not significant, the plastic elements are not needed and without plastic elements, the rheological models are generally called visco-elastic models.

Throughout the years, a number of visco-elastic models have been developed for concrete creep (Bazant, 1982; Bazant and Wu, 1974; Creus, 1986; Neville et al., 1983). These include the Maxwell model, Kelvin model, Burgers model, Bingham model and their variations. All of them comprise an elastic spring to account for instant elastic deformation and several units to account for time-dependent creep deformation. Among the wide spectrum of models, the generalised Maxwell model (formed by connecting Maxwell units in parallel) and the generalised Kelvin model (formed by connecting Kelvin units in series) are the most versatile for the approximation of creep functions (Bazant, 1982).

\subsection{Remnant-creep-based visco-elastic model}

Herein, a new numerical implementation based on the multi-unit visco-elastic creep model, as shown in Figure 2, is proposed. The model is made up of two parts connected in series as for the other existing models. The first part is an elastic spring for simulating the instant elastic deformation. The second part is an assemblage of repeated units connected in series for simulating the time-dependent creep deformation. Each repeated unit comprises an elastic spring and a damper connected in parallel. The

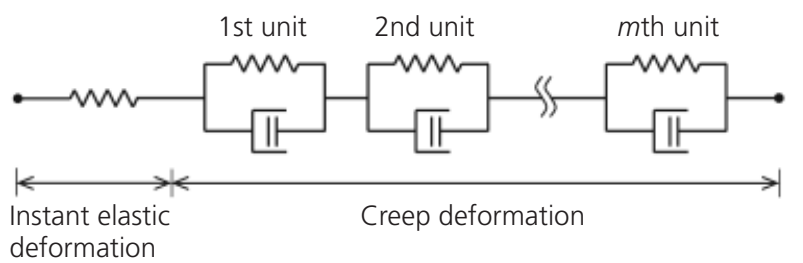

Figure 2. Proposed multi-unit visco-elastic creep model number of repeated units in the model can be varied to suit the creep characteristics of the concrete.

Under the framework of the multi-unit visco-elastic model, the creep coefficient $\phi(t, \tau)$ can be expressed in the form of a Dirichlet series as follows

6

$$
\phi(t, \tau)=\phi(\infty, \tau) \sum_{j=1}^{m} c_{\mathrm{v} j}\left\{1-\exp \left[-\omega_{\mathrm{v} j}(t-\tau)\right]\right\}
$$

where $m$ is the number of repeated units in the model, and $c_{\mathrm{v} j}$ and $\omega_{\mathrm{v} j}$ are respectively the weighting coefficient and characteristic rate of the $j$ th unit. The weighting coefficient $c_{\mathrm{v} j}$ represents the fraction of creep strain allocated to the $j$ th unit. To ensure that the creep strains of the $m$ number of units would add up to the actual creep strain, the sum of all weighting coefficients is always set equal to unity.

It is proposed herein to incorporate in the analysis also the remnant creep strain: that is, the remaining portion of the ultimate creep strain which is yet to take place. As a complement of the creep coefficient, the remnant creep coefficient $\phi_{\mathrm{r}}(t, \tau)$ is defined as follows

$$
\begin{aligned}
\phi_{\mathrm{r}}(t, \tau) & =\phi(\infty, \tau)-\phi(t, \tau) \\
& =\phi(\infty, \tau) \sum_{j=1}^{m} c_{\mathrm{v} j} \exp \left[-\omega_{\mathrm{v} j}(t-\tau)\right]
\end{aligned}
$$

For a stress history consisting of a constant stress $\sigma_{\mathrm{c}}\left(t_{0}\right)$ applied at time $t_{0}$ and stress increments $\partial \sigma_{\mathrm{c}}(\tau)$ each applied at time $\tau$ from $t_{0}$ to $t$, the remnant creep strain $\varepsilon_{\mathrm{rc}}\left(t, t_{0}\right)$ is given by

8

$$
\varepsilon_{\mathrm{rc}}\left(t, t_{0}\right)=\phi_{\mathrm{r}}\left(t, t_{0}\right) \frac{\sigma_{\mathrm{c}}\left(t_{0}\right)}{E_{\mathrm{c}}\left(t_{0}\right)}+\int_{\tau=t_{0}}^{t} \phi_{\mathrm{r}}(t, \tau) \frac{\partial \sigma_{\mathrm{c}}(\tau)}{E_{\mathrm{c}}(\tau)}
$$

Substituting the formula for $\phi_{\mathrm{r}}(t, \tau)$ into the above equation, the remnant creep strain $\varepsilon_{\mathrm{rc}}\left(t, t_{0}\right)$ may be determined as

9. $\varepsilon_{\mathrm{rc}}\left(t, t_{0}\right)=\sum_{j=1}^{m} \varepsilon_{\mathrm{vj}}\left(t, t_{0}\right)$

where $\varepsilon_{\mathrm{v} j}\left(t, t_{0}\right)$ is the remnant creep strain in the $j$ th unit given by 


$$
\begin{aligned}
\varepsilon_{\mathrm{v} j}\left(t, t_{0}\right)= & \phi\left(\infty, t_{0}\right) \frac{\sigma_{\mathrm{c}}\left(t_{0}\right)}{E_{\mathrm{c}}\left(t_{0}\right)} c_{v \mathrm{j}} \exp \left[-\omega_{\mathrm{vj}}\left(t-t_{0}\right)\right] \\
& +\int_{\tau=t_{0}}^{t} \phi(\infty, \tau) \frac{\partial \sigma_{\mathrm{c}}(\tau)}{E_{\mathrm{c}}(\tau)} c_{\mathrm{vj}} \exp \left[-\omega_{\mathrm{v} j}(t-\tau)\right]
\end{aligned}
$$

On the other hand, substituting the formula for $\phi(t, \tau)$ into Equation 5 and differentiating with respect to the time $t$, the rate of change of creep strain with time may be derived as

$$
\begin{aligned}
& \frac{\partial \varepsilon_{c c}\left(t, t_{0}\right)}{\partial t}= \\
& \quad \sum_{j=1}^{m} \phi\left(\infty, t_{0}\right) \frac{\sigma_{c}\left(t_{0}\right)}{E_{c}\left(t_{0}\right)} c_{v j} \omega_{v j} \exp \left[-\omega_{v j}\left(t-t_{0}\right)\right] \\
& \quad+\sum_{j=1}^{m} \int_{\tau=t_{0}}^{t} \phi(\infty, \tau) \frac{\partial \sigma_{c}(\tau)}{E_{c}(\tau)} c_{v j} \omega_{v j} \exp \left[-\omega_{v j}(t-\tau)\right]
\end{aligned}
$$

Rearranging, the formula for the incremental creep strain at time $t$ becomes

$$
\partial \varepsilon_{\mathrm{cc}}\left(t, t_{0}\right)=\left[\sum_{j=1}^{m} \omega_{\mathrm{vj}} \varepsilon_{\mathrm{vj}}\left(t, t_{0}\right)\right] \partial t
$$

The above formula for the incremental creep strain is astonishingly simple. More importantly, it is not directly dependent on the stress history. The implication is that if we use the remnant creep strains to evaluate the incremental creep strains, there is no longer any necessity to memorise the stress histories of the concrete elements.

\subsection{Numerical implementation}

Although there is no longer any necessity to memorise the stress history, it is now necessary to evaluate the remnant creep strain at each time step. For the first time step, the remnant creep strain $\varepsilon_{\mathrm{v} j}\left(t_{0}, t_{0}\right)$ in the $j$ th unit at time $t_{0}$ is given by

$$
\varepsilon_{\mathrm{v} j}\left(t_{0}, t_{0}\right)=\phi\left(\infty, t_{0}\right) \frac{\sigma_{\mathrm{c}}\left(t_{0}\right)}{E_{\mathrm{c}}\left(t_{0}\right)} c_{\mathrm{v} j}
$$

Consider the $i$ th time step in the analysis. Let the beginning time and ending time of the time step be $t_{i-1}$ and $t_{i}$, respectively. The increment in remnant creep strain $\Delta \varepsilon_{\mathrm{v} j}$ can be determined by substituting $t_{i-1}$ and $t_{i}$ in turn into Equation 10 in place of $t$ to obtain $\varepsilon_{\mathrm{v} j}\left(t_{i-1}, t_{0}\right)$ and $\varepsilon_{\mathrm{v} j}\left(t_{i}, t_{0}\right)$, and subtracting $\varepsilon_{\mathrm{v} j}\left(t_{i-1}, t_{0}\right)$ from $\varepsilon_{\mathrm{v} j}\left(t_{i}, t_{0}\right)$ as

$$
\begin{gathered}
\Delta \varepsilon_{\mathrm{v} j}=\varepsilon_{\mathrm{v} j}\left(t_{i-1}, t_{0}\right)\left[\exp \left(-\omega_{\mathrm{v} j} \Delta t\right)-1\right] \\
+\phi\left(\infty, t_{i-1}\right) \frac{\Delta \sigma_{\mathrm{c}}\left(t_{i-1}\right)}{E_{\mathrm{c}}\left(t_{i-1}\right)} c_{\mathrm{v} j}
\end{gathered}
$$

where $\Delta t=t_{i}-t_{i-1}$. Since $\varepsilon_{\mathrm{v} j}\left(t_{i}, t_{0}\right)=\varepsilon_{\mathrm{v} j}\left(t_{i-1}, t_{0}\right)+\Delta \varepsilon_{\mathrm{v} j}$, the remnant creep strain $\varepsilon_{\mathrm{v} j}\left(t_{i}, t_{0}\right)$ may be obtained directly from the remnant creep strain $\varepsilon_{\mathrm{v} j}\left(t_{i-1}, t_{0}\right)$ as

$$
\begin{aligned}
\varepsilon_{\mathrm{v} j}\left(t_{i}, t_{0}\right)= & \varepsilon_{\mathrm{v} j}\left(t_{i-1}, t_{0}\right) \exp \left(-\omega_{\mathrm{v} j} \Delta t\right) \\
& +\phi\left(\infty, t_{i-1}\right) \frac{\Delta \sigma_{\mathrm{c}}\left(t_{i-1}\right)}{E_{\mathrm{c}}\left(t_{i-1}\right)} c_{\mathrm{v} j}
\end{aligned}
$$

The first term in the right-hand side of the above equation represents the decaying remnant creep, whereas the second term represents the contribution of current stress increment. From Equations 13 and 15, the remnant creep strain at every time step can be evaluated. It should be noted that only the remnant creep strain at the previous time step $\varepsilon_{\mathrm{v} j}\left(t_{i-1}, t_{0}\right)$ and the current stress increment $\Delta \sigma_{\mathrm{c}}\left(t_{i-1}\right)$ but not the stress history are involved in the formulation.

Having obtained the remnant creep strains, the incremental creep strain at $i$ th time step can be determined as

16. $\Delta \varepsilon_{\mathrm{cc}}\left(t_{i-1}, t_{0}\right)=\left[\sum_{j=1}^{m} \omega_{\mathrm{vj}} \varepsilon_{\mathrm{vj}}^{\prime}\left(t_{i}, t_{i-1}\right)\right] \Delta t$

where $\varepsilon_{\mathrm{vj}}^{\prime}\left(t_{i}, t_{i-1}\right)$ is the mean value of $\varepsilon_{\mathrm{v} j}\left(t, t_{0}\right)$ within the time step. For simplicity, the value of $\varepsilon_{\mathrm{vj}}^{\prime}\left(t_{i}, t_{i-1}\right)$ may be taken as the average of $\varepsilon_{\mathrm{v} j}\left(t_{i-1}, t_{0}\right)$ and $\varepsilon_{\mathrm{v} j}\left(t_{i}, t_{0}\right)$. From the incremental creep strain, the creep strain at time $t_{i}$ may be obtained as

17.

$$
\varepsilon_{\mathrm{cc}}\left(t_{i}, t_{0}\right)=\varepsilon_{\mathrm{cc}}\left(t_{i-1}, t_{0}\right)+\left[\sum_{j=1}^{m} \omega_{\mathrm{vj}} \varepsilon_{\mathrm{vj}}^{\prime}\left(t_{i}, t_{i-1}\right)\right] \Delta t
$$

Again, it should be noted that only the remnant creep strains $\varepsilon_{\mathrm{v} j}\left(t_{i-1}, t_{0}\right)$ and $\varepsilon_{\mathrm{v} j}\left(t_{i}, t_{0}\right)$, and the creep strain at the previous time step $\varepsilon_{\mathrm{cc}}\left(t_{i-1}, t_{0}\right)$ but not the stress history are involved in the formulation. Hence, the proposed model enables the evaluation of creep strain without entangling with the memorisation of stress histories.

\section{Application with design codes}

The proposed multi-unit visco-elastic model has been incorporated into a finite-element structural analysis program developed by the authors for the analysis of concrete structures using the creep formulas stipulated in the design codes. The codified creep 
formulas implemented are those in the CEB-FIP model code 1990 (CEB, 1993), ACI Committee 209 report (ACI, 1992), British Standard BS 5400: Part 4 (BSI, 1990), and Eurocode 2: Part 2 (CEN, 2005). For ease of reading, the symbols used hereafter follow the respective design codes, except where clarifications are made.

\subsection{CEB-FIP model code 1990 (MC-90)}

Unlike the other creep models, the creep coefficient $\phi_{28}\left(t, t_{0}\right)$ in MC-90 is defined in terms of the elastic modulus $E_{\mathrm{c}}(28)$ at the age of $28 \mathrm{~d}$ : that is

18. $\varepsilon_{\mathrm{cc}}\left(t, t_{0}\right)=\phi_{28}\left(t, t_{0}\right) \frac{\sigma_{\mathrm{c}}\left(t_{0}\right)}{E_{\mathrm{c}}(28)}$

The creep coefficient in the above equation is given by

19. $\phi_{28}\left(t, t_{0}\right)=\phi_{0} \beta_{\mathrm{c}}\left(t-t_{0}\right)$

in which $\phi_{0}$ denotes the notional creep coefficient, which is dependent on the notional size of member, the environmental conditions, the compressive strength of concrete and the age of concrete at load application. The time function $\beta_{\mathrm{c}}\left(t-t_{0}\right)$ describes the development of creep with time and is given by

20. $\beta_{\mathrm{c}}\left(t-t_{0}\right)=\left[\frac{\left(t-t_{0}\right)}{\beta_{\mathrm{H}, \mathrm{T}}+\left(t-t_{0}\right)}\right]^{0 \cdot 3}$

where the coefficient $\beta_{\mathrm{H}, \mathrm{T}}$ is a function of the environmental conditions and the notional size of member.

From the above equation, the creep half-time $t_{0.5}$ (the time for half of the ultimate creep to take place) may be evaluated as

21. $t_{0 \cdot 5}=\frac{\beta_{\mathrm{H}, \mathrm{T}}}{0 \cdot 5^{-1 / 0 \cdot 3}-1}$

By curve-fitting, it is found that a four-unit visco-elastic model $(m=4)$ is able to fit very closely the time function in MC-90. The parameters of the four-unit model are: $c_{\mathrm{v} 1}=0.3279$, $c_{\mathrm{v} 2}=0 \cdot 2939, c_{\mathrm{v} 3}=0 \cdot 2556, c_{\mathrm{v} 4}=0 \cdot 1225, \omega_{\mathrm{v} 1}=6 \omega_{v}, \omega_{\mathrm{v} 2}=\omega_{\mathrm{v}}$, $\omega_{\mathrm{v} 3}=(1 / 6) \omega_{\mathrm{v}}$ and $\omega_{\mathrm{v} 4}=(1 / 36) \omega_{\mathrm{v}}$, where $\omega_{\mathrm{v}}\left(=-\ln (0 \cdot 5) / t_{0.5}\right)$ is the value for a one-unit model that will give the same creep half-time. The MC-90 creep model and the proposed four-unit model are compared in Figure 3, from which it can be seen that nearly perfect agreement has been achieved.

It is noteworthy that in the creep model of Eurocode 2: Part 1-1 (CEN, 2004), the time function $\beta_{\mathrm{c}}\left(t-t_{0}\right)$ is the same as that given in Equation 20, albeit the notional creep coefficient $\phi_{0}$ is distinct

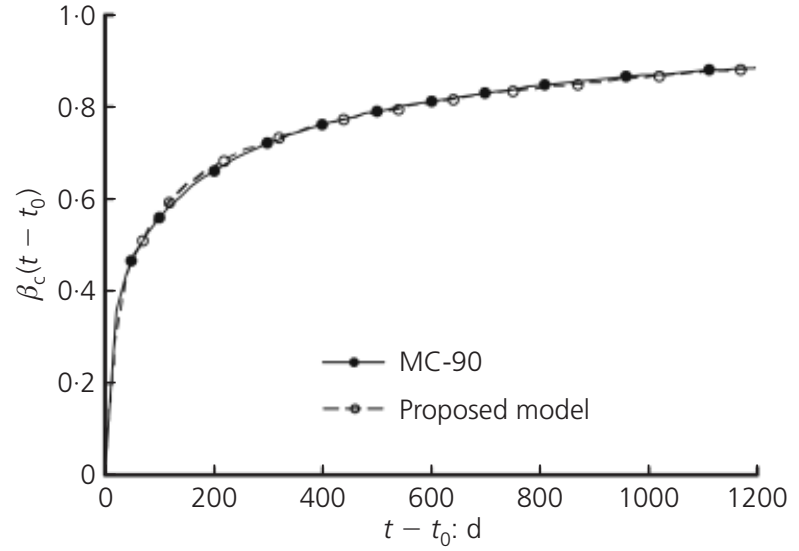

Figure 3. Comparison of MC-90 with proposed model

from that in MC-90. Moreover, an update of MC-90, known as FIB model code 2010 (MC-10), has recently been drafted and published (FIB, 2012). The creep model of MC-10 is essentially the same as that of MC-90, except slight modifications of the $\phi_{0}$ and $\beta_{\mathrm{H}, \mathrm{T}}$ formulas to allow for the effect of concrete strength. Its time function $\beta_{c}\left(t-t_{0}\right)$ is the same as that in MC-90. Hence, the above set of $c_{\mathrm{v} j}$ and $\omega_{\mathrm{v} j}$ values is also applicable to Eurocode 2: Part 1-1 and MC-10.

\subsection{ACl Committee 209 report: 1992 (ACl 209)}

According to ACI 209, the creep coefficient $v_{\mathrm{t}}$ may be evaluated as the product of ultimate creep coefficient $v_{\mathrm{u}}$ and a time function $\beta_{\mathrm{c}}(t)$, as given by

22. $v_{\mathrm{t}}=v_{\mathrm{u}} \beta_{\mathrm{c}}(t)$

in which $v_{\mathrm{u}}$ is product of a constant and several multipliers

23. $v_{\mathrm{u}}=2 \cdot 35 \gamma_{\mathrm{la}} \gamma_{\mathrm{rh}} \gamma_{\mathrm{h}} \gamma_{\mathrm{s}} \gamma_{\mathrm{fa}} \gamma_{\alpha}$

The multipliers $\gamma_{\mathrm{la}}, \gamma_{\mathrm{rh}}, \gamma_{\mathrm{h}}, \gamma_{\mathrm{s}}, \gamma_{\mathrm{fa}}$ and $\gamma_{\alpha}$ are to allow for the effects of loading age, relative humidity, effective thickness, slump, fine to total aggregate ratio and air content, respectively. On the other hand, the time function $\beta_{\mathrm{c}}(t)$ is given by

24. $\beta_{\mathrm{c}}(t)=\frac{t^{0 \cdot 6}}{10+t^{0 \cdot 6}}$

Somehow, the above time function is independent of the environmental conditions and the notional size of member. From the above equation, the creep half-time $t_{0.5}$ may be evaluated as

25. $t_{0.5}=10^{1 / 0 \cdot 6}$ 
By curve-fitting, it is found that a four-unit visco-elastic model $(m=4)$ is able to fit very closely the time function in ACI 209. The parameters of the four-unit model are: $c_{\mathrm{v} 1}=0.2886$, $c_{\mathrm{v} 2}=0 \cdot 3943, c_{\mathrm{v} 3}=0 \cdot 1661, c_{\mathrm{v} 4}=0 \cdot 1511, \omega_{\mathrm{v} 1}=8 \omega_{\mathrm{v}}, \omega_{\mathrm{v} 2}=\omega_{\mathrm{v}}$, $\omega_{\mathrm{v} 3}=(1 / 8) \omega_{\mathrm{v}}$ and $\omega_{\mathrm{v} 4}=(1 / 64) \omega_{\mathrm{v}}$, where $\omega_{\mathrm{v}}\left(=-\ln (0 \cdot 5) / t_{0.5}\right)$ is the value for a one-unit model that will give the same creep half-time. The ACI 209 creep model and the proposed four-unit model are compared in Figure 4, which demonstrates excellent agreement.

\subsection{British Standard BS 5400: Part 4: 1990 (BS 5400)}

In the creep model of BS 5400, the creep coefficient $\phi$ is evaluated as the product of five partial coefficients, as given by

26. $\phi=K_{\mathrm{L}} K_{\mathrm{m}} K_{\mathrm{c}} K_{\mathrm{e}} K_{j}$

where $K_{\mathrm{L}}$ depends on the relative humidity, $K_{\mathrm{m}}$ depends on the maturity of concrete at the age of loading, $K_{\mathrm{c}}$ depends on the composition of the concrete, $K_{\mathrm{e}}$ depends on the effective thickness $h_{\mathrm{e}}$ of the member (defined as the ratio of cross-sectional area of member to half the perimeter in contact with the atmosphere) and $K_{j}$ defines the development of creep with time $t$. The partial coefficients $K_{\mathrm{L}}, K_{\mathrm{m}}, K_{\mathrm{c}}, K_{\mathrm{e}}$ and $K_{j}$ are presented in the form of graphs.

To facilitate direct computation of the various coefficients, Alexander (2002) converted the graphs for the partial coefficients into formulas. The time-dependent partial coefficient $K_{j}$ was formulated as

27. $K_{j}=\frac{t^{0 \cdot 8}}{250 h_{\mathrm{e}}+t^{0 \cdot 8}}$

from which the creep half-time $t_{0.5}$ may be evaluated as

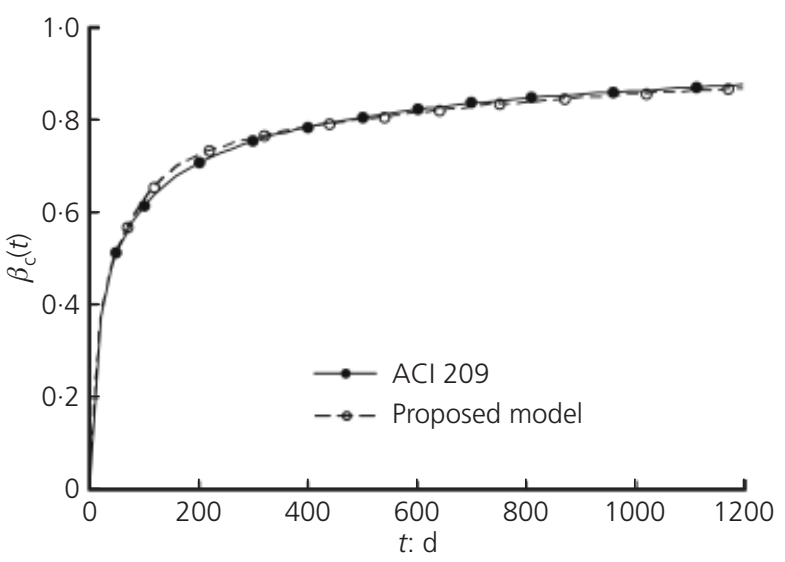

Figure 4. Comparison of $\mathrm{ACl} 209$ with proposed model
28. $t_{0 \cdot 5}=\left(250 h_{\mathrm{e}}\right)^{1 \cdot 25}$

By curve-fitting, it is found that a four-unit visco-elastic model $(m=4)$ is able to fit very closely the time function in BS 5400 . The parameters of the four-unit model are: $c_{\mathrm{v} 1}=0 \cdot 3040$, $c_{\mathrm{v} 2}=0.3666, c_{\mathrm{v} 3}=0.1522, c_{\mathrm{v} 4}=0.1772, \omega_{\mathrm{v} 1}=4 \omega_{\mathrm{v}}, \omega_{\mathrm{v} 2}=\omega_{\mathrm{v}}$, $\omega_{\mathrm{v} 3}=(1 / 4) \omega_{\mathrm{v}}$ and $\omega_{\mathrm{v} 4}=(1 / 16) \omega_{\mathrm{v}}$, where $\omega_{v}\left(=-\ln (0 \cdot 5) / t_{0.5}\right)$ is the value for a one-unit model that will give the same creep half-time. The BS 5400 creep model and the proposed four-unit model are compared in Figure 5, from which it can be seen that very close agreement has been achieved.

\subsection{Eurocode 2: Part 2: 2005 (Eurocode 2-2)}

Whereas the creep model in Eurocode 2: Part 1-1 (Eurocode 2-1-1) is similar to that in MC-90, the creep model in Eurocode 2: Part 2 (Eurocode 2-2), which is specifically for high-strength concrete, is quite different. In Eurocode 2-2, the creep of concrete is explicitly separated into two components, namely basic creep and drying creep, and the creep strain is evaluated in terms of the basic creep coefficient $\phi_{\mathrm{b}}\left(t, t_{0}\right)$ and drying creep coefficient $\phi_{\mathrm{d}}\left(t, t_{0}\right)$, as follows

29. $\varepsilon_{\mathrm{cc}}\left(t, t_{0}\right)=\left[\phi_{\mathrm{b}}\left(t, t_{0}\right)+\phi_{\mathrm{d}}\left(t, t_{0}\right)\right] \frac{\sigma_{\mathrm{c}}\left(t_{0}\right)}{E_{\mathrm{c}}}$

The basic creep coefficient $\phi_{\mathrm{b}}\left(t, t_{0}\right)$ is given by

30. $\phi_{\mathrm{b}}\left(t, t_{0}\right)=\phi_{\mathrm{b} 0} \beta_{\mathrm{c}}\left(t-t_{0}\right)$

where $\phi_{\mathrm{b} 0}$ is dependent on the strength, composition and age at load application of the concrete and the time function $\beta_{\mathrm{c}}\left(t-t_{0}\right)$ is formulated as

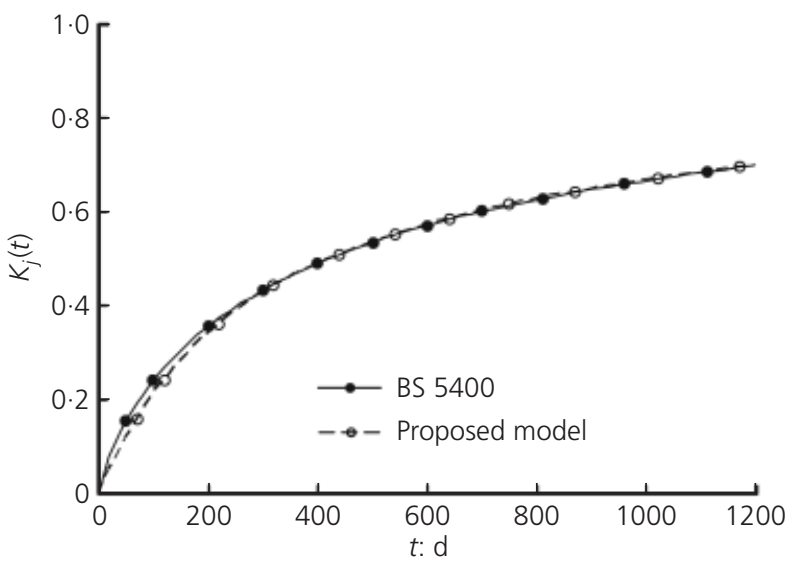

Figure 5. Comparison of BS 5400 with proposed model 
31. $\beta_{\mathrm{c}}\left(t-t_{0}\right)=\frac{\left(t-t_{0}\right)^{0 \cdot 5}}{\beta_{\mathrm{bc}}+\left(t-t_{0}\right)^{0 \cdot 5}}$

in which $\beta_{\mathrm{bc}}$ is dependent on the composition and age at load application of the concrete. On the other hand, the drying creep coefficient $\phi_{\mathrm{d}}\left(t, t_{0}\right)$ is given by

32. $\phi_{\mathrm{d}}\left(t, t_{0}\right)=\phi_{\mathrm{d} 0}\left[\varepsilon_{\mathrm{cd}}(t)-\varepsilon_{\mathrm{cd}}\left(t_{0}\right)\right]$

where $\phi_{\mathrm{d} 0}$ is dependent on the composition of concrete, and $\varepsilon_{\mathrm{cd}}(t)$ is the drying shrinkage strain of concrete at time $t$.

In the time-step analysis, the drying creep component may be determined simply by cumulating the incremental drying creep strain at each time step. This procedure does not involve memorisation of the stress history and hence prediction of drying creep by visco-elasticity modelling is not recommended. Only the basic creep component needs to be modelled by the proposed visco-elastic model. From Equation 31, the basic creep half-time $t_{0.5}$ may be evaluated as

33. $t_{0 \cdot 5}=\beta_{\mathrm{bc}}^{2}$

By curve-fitting, it is found that a four-unit visco-elastic model $(m=4)$ is able to fit very closely the time function for the basic creep strain in Eurocode 2-2. The parameters of the four-unit model are: $c_{\mathrm{v} 1}=0.3139, \quad c_{\mathrm{v} 2}=0.3511, \quad c_{\mathrm{v} 3}=0.1137, \quad c_{\mathrm{v} 4}=$ $0 \cdot 2213, \omega_{\mathrm{v} 1}=8 \omega_{\mathrm{v}}, \omega_{\mathrm{v} 2}=\omega_{\mathrm{v}}, \omega_{\mathrm{v} 3}=(1 / 8) \omega_{\mathrm{v}}$ and $\omega_{\mathrm{v} 4}=(1 / 64)$ $\omega_{\mathrm{v}}$, where $\omega_{\mathrm{v}}\left(=-\ln (0 \cdot 5) / t_{0.5}\right)$ is the value for a one-unit model that will give the same creep half-time. The time function for the basic creep strain in the Eurocode 2-2 creep model and the time function of the proposed four-unit model are compared in Figure 6 , from which very good agreement can be seen.

\subsection{Comparison of design codes}

From the preceding section, it is seen that for all the design codes considered, the creep time functions can be represented very accurately by the proposed multi-unit visco-elastic model with $m=4$. In other words, a four-unit visco-elastic model is accurate enough for practical applications with the design codes. The set of $c_{\mathrm{v} j}$ and $\omega_{\mathrm{v} j}$ values for the creep time function in each of the design codes are summarised in Table 1. It should, however, be noted that the proposed multi-unit visco-elastic model is completely general and its application is not limited to the above design codes. In theory, the proposed multi-unit visco-elastic model may be used to fit any creep time functions, including those derived directly from creep tests of concrete.

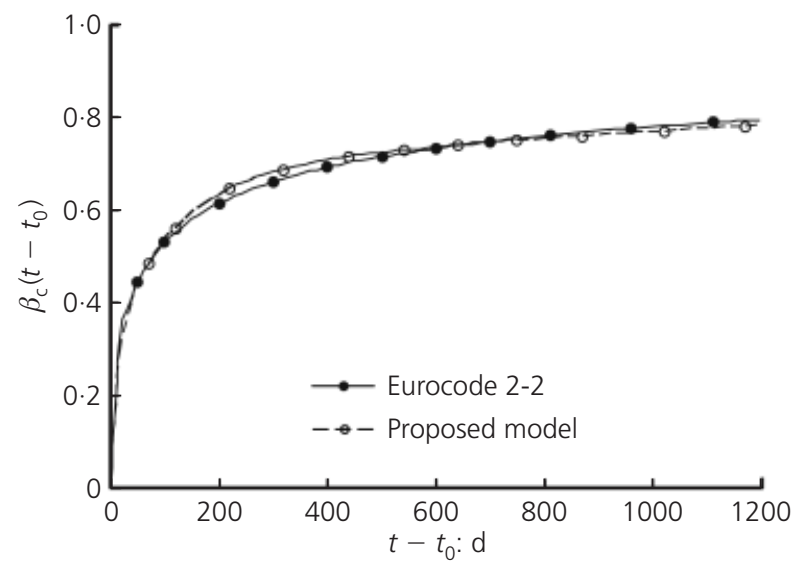

Figure 6. Comparison of Eurocode 2-2 with proposed model

\begin{tabular}{|c|c|c|c|c|}
\hline \multirow[t]{2}{*}{ Parameter } & \multicolumn{4}{|c|}{ Design code } \\
\hline & $\begin{array}{c}\text { MC-90 } \\
\text { (and draft MC-10) }\end{array}$ & ACI 209 & BS 5400 & EC2-2 \\
\hline$m$ & 4 & 4 & 4 & 4 \\
\hline$c_{\mathrm{v} 1}$ & $0 \cdot 3279$ & $0 \cdot 2886$ & $0 \cdot 3040$ & $0 \cdot 3139$ \\
\hline$c_{\mathrm{v} 2}$ & 0.2939 & 0.3943 & $0 \cdot 3666$ & $0 \cdot 3511$ \\
\hline $\mathrm{C}_{\mathrm{v} 3}$ & $0 \cdot 2556$ & $0 \cdot 1661$ & $0 \cdot 1522$ & $0 \cdot 1137$ \\
\hline$c_{\mathrm{v} 4}$ & $0 \cdot 1225$ & $0 \cdot 1511$ & $0 \cdot 1772$ & $0 \cdot 2213$ \\
\hline$\omega_{\mathrm{v} 1}$ & $6 \omega_{v}$ & $8 \omega_{v}$ & $4 \omega_{v}$ & $8 \omega_{v}$ \\
\hline$\omega_{\mathrm{v} 2}$ & $\omega_{\vee}$ & $\omega_{\mathrm{v}}$ & $\omega_{v}$ & $\omega_{\mathrm{v}}$ \\
\hline$\omega_{\mathrm{v} 3}$ & $(1 / 6) \omega_{v}$ & $(1 / 8) \omega_{v}$ & $(1 / 4) \omega_{v}$ & $(1 / 8) \omega_{v}$ \\
\hline$\omega_{\mathrm{v} 4}$ & $(1 / 36) \omega_{\mathrm{v}}$ & $(1 / 64) \omega_{v}$ & $(1 / 16) \omega_{\vee}$ & $(1 / 64) \omega_{\mathrm{v}}$ \\
\hline$t_{0.5}$ & $\beta_{\mathrm{H}, \mathrm{T}} /\left(0 \cdot 5^{-1 / 0 \cdot 3}-1\right)$ & $10^{1 / 0 \cdot 6}$ & $\left(250 h_{\mathrm{e}}\right)^{1 \cdot 25}$ & $\beta_{\mathrm{bc}}^{2}$ \\
\hline$\omega_{\vee}$ & $-\ln (0.5) / t_{0.5}$ & $-\ln (0.5) / t_{0.5}$ & $-\ln (0.5) / t_{0.5}$ & $-\ln (0 \cdot 5) / t_{0.5}$ \\
\hline
\end{tabular}

Table 1. Parameter values of proposed multi-unit visco-elastic model 


\section{Examples of time-step finite-element analysis}

Two numerical examples are presented to demonstrate the applicability of the proposed visco-elastic model. In these examples, tensile stress is taken as positive and compressive stress is taken as negative.

\subsection{Example 1: restrained concrete prism}

A uniaxially restrained plain concrete prism is analysed for the axial stresses induced by shrinkage and creep effects. The concrete prism is $500 \mathrm{~mm}$ long and has a uniform cross-section of $75 \mathrm{~mm}$ by $75 \mathrm{~mm}$, as shown in Figure 7(a). Its ends are perfectly restrained such that axial movement is totally prevented. Drying is allowed from all four side faces so that the notional size of the concrete prism is $37.5 \mathrm{~mm}$. The prism is cast of concrete having a mean $28 \mathrm{~d}$ cylinder compressive strength of 37.0 MPa. It is wet cured during the first day after casting and thereafter kept in an environment with a constant temperature of $23^{\circ} \mathrm{C}$ and a relative humidity of $50 \%$. The time at which drying starts is denoted by $t_{\mathrm{s}}$ (day).

The shrinkage and creep models in MC-90 (CEB, 1993) are employed for the analysis. To verify the applicability and accuracy of the proposed remnant-creep-based visco-elastic model with $m=4$, the analysis is carried out twice, first using the conventional approach of storing the stress history and evaluating the creep strains by time-integration of creep responses, and then using the proposed approach of evaluating the incremental creep strains at each time step from the remnant creep strains without

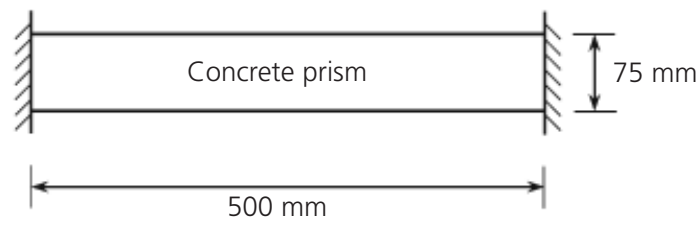

(a)

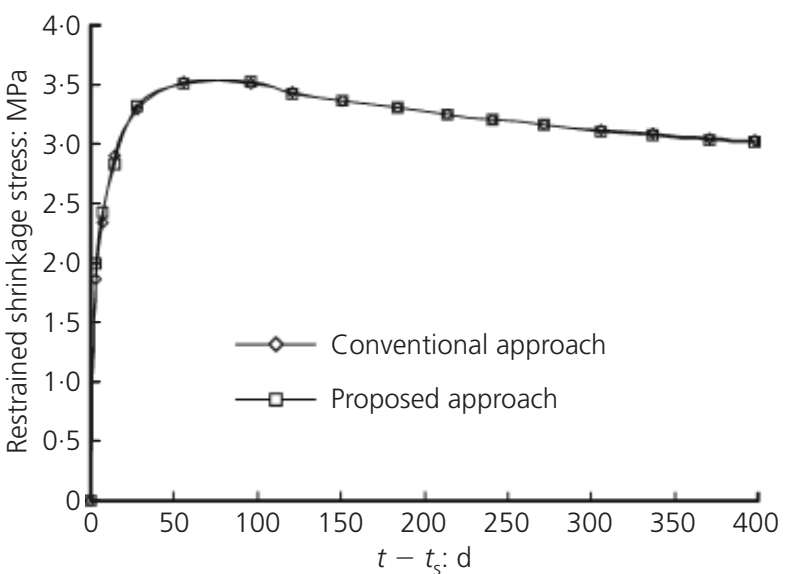

(b)

Figure 7. Restrained concrete prism: (a) schematic representation of prism; (b) time variation of restrained shrinkage stress storing the stress history. In applying the conventional approach or the proposed approach, 61 time steps are used in the numerical analyses and the demarcation of time steps follows basically a geometrical progression (Kwan and $\mathrm{Ng}$, 2009; $\mathrm{Ng}$ et al., 2007). The respective computed tensile stresses-time curves so obtained are plotted in Figure 7(b). It is seen that regardless of the method used for the analysis, the computed tensile stress increases from zero to a maximum value of about $3.5 \mathrm{MPa}$ owing to the effect of shrinkage restraint and then decreases gradually due to the effect of creep (analogous to stress relaxation). The good agreement between the two curves in Figure 7(b) verifies the accuracy of the proposed remnant-creep-based visco-elastic model.

\subsection{Example 2: concrete podium structure}

A concrete podium structure with its floor slab structurally connected to a number of beams and columns, and two core walls supporting tower blocks on top, as shown in Figure 8(a), is analysed. The podium structure is $90.0 \mathrm{~m}$ long and $42.0 \mathrm{~m}$ wide, and has a storey height of $3.5 \mathrm{~m}$. The slab has a constant thickness of $200 \mathrm{~mm}$ and is cast of concrete having a $28 \mathrm{~d}$ cylinder compressive strength of $37.0 \mathrm{MPa}$. It is provided with steel reinforcing bars along the $x$ - and $y$-axes, and the steel ratios in both directions are $0.4 \%$. All the beams have a uniform crosssection of $500 \mathrm{~mm}$ by $500 \mathrm{~mm}$ and are cast of the same concrete as the slab. They all have the same steel ratio of $1.0 \%$. All the columns have a uniform cross-section of $600 \mathrm{~mm}$ by $600 \mathrm{~mm}$ and

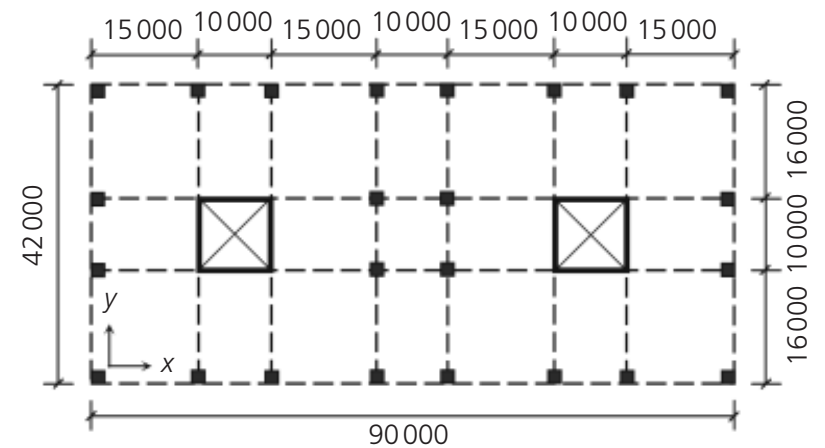

Legend:

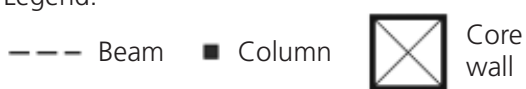

(a)

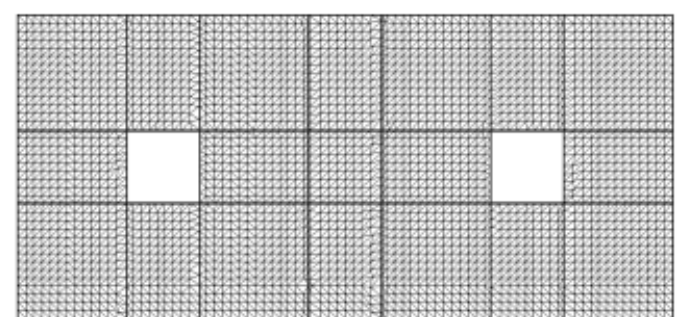

(b)

Figure 8. Concrete podium structure: (a) structural plan; (b) finiteelement mesh. All dimensions in $\mathrm{mm}$ 
are cast of concrete having a $28 \mathrm{~d}$ cylinder compressive strength of $48.0 \mathrm{MPa}$. Their steel ratios are $2.0 \%$. The two core walls have a constant wall thickness of $500 \mathrm{~mm}$ and are cast of the same concrete as the columns. Their steel ratios in both the horizontal and vertical directions are $1.0 \%$. The tensile strength and elastic modulus of the beam and slab concrete are $2.9 \mathrm{MPa}$ and $33.55 \mathrm{GPa}$ respectively while the tensile strength and elastic modulus of the column and wall concrete are $3.5 \mathrm{MPa}$ and $36.27 \mathrm{GPa}$ respectively. The Poisson's ratio of concrete is assumed to be $0 \cdot 18$. Lastly, the elastic modulus of reinforcing steel is taken as $200 \mathrm{GPa}$.

The construction of the columns and core walls is $7 \mathrm{~d}$ ahead of the slab. The wet curing period of all concrete members is $3 \mathrm{~d}$ : that is, the concrete starts to dry and shrink $3 \mathrm{~d}$ after it is cast. It is assumed that the ambient temperature is $27^{\circ} \mathrm{C}$ and the relative humidity is $75 \%$ throughout the period of analysis. The shrinkage and creep models in MC-90 are employed for evaluation of shrinkage and creep strains whereas the finite-element mesh generated for the finite-element analysis is shown in Figure 8(b). A total of 6032 plane stress elements were used to model the podium structure. As in the previous example, the analysis is carried out twice, first using the conventional time-integration formulation approach and then using the proposed remnant creep formulation approach. In applying the conventional approach or the proposed approach, the number of time steps used in the analysis was 69 and the demarcation of time steps followed basically a geometrical progression (Kwan and $\mathrm{Ng}, 2009$; $\mathrm{Ng}$ et al., 2007).

Slab elements whose major principal stress exceeds the tensile strength of concrete are considered prone to cracking, and the potential crack direction in each element prone to cracking is taken as perpendicular to the direction of the major principal stress. The contours of major principal stresses as well as the potential crack directions (marked by short straight lines) at $365 \mathrm{~d}$ after casting of the floor slab based on the conventional approach are plotted in Figure 9(a), whereas those based on the proposed approach are plotted in Figure 9(b) for comparison. To reveal the long-term effects, the analysis results at $1095 \mathrm{~d}$ ( 3 years) after casting of the floor slab based on the conventional approach and the proposed approach are plotted in Figures 10(a) and 10(b), respectively, which show virtually identical stress contours and areas prone to cracking. More importantly, in extending the analysis period from $365 \mathrm{~d}$ to $1095 \mathrm{~d}$, the required computer memory tripled from an already very high level when the conventional approach was adopted, but the required computer memory remained at the same low level when the proposed approach was adopted. The economisation of computer memory requirement is not at the expense of accuracy. Comparing Figure 9(a) with Figure 9(b), as well as Figure 10(a) with Figure 10(b), it can be seen that excellent agreement between the numerical results obtained by the two approaches has been achieved. Hence, the proposed approach is numerically equivalent to the conventional approach.

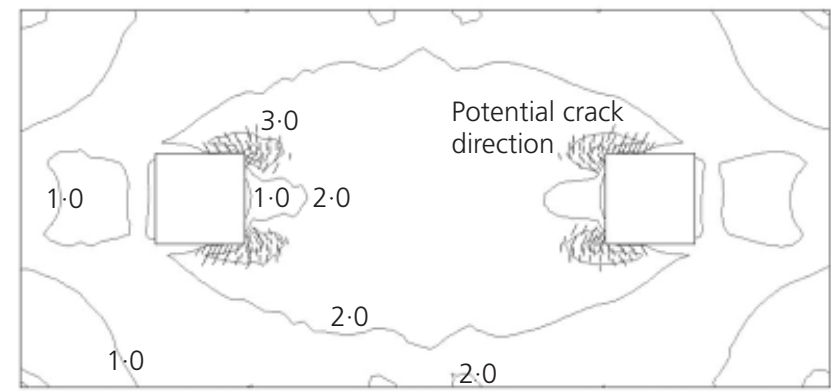

(a)

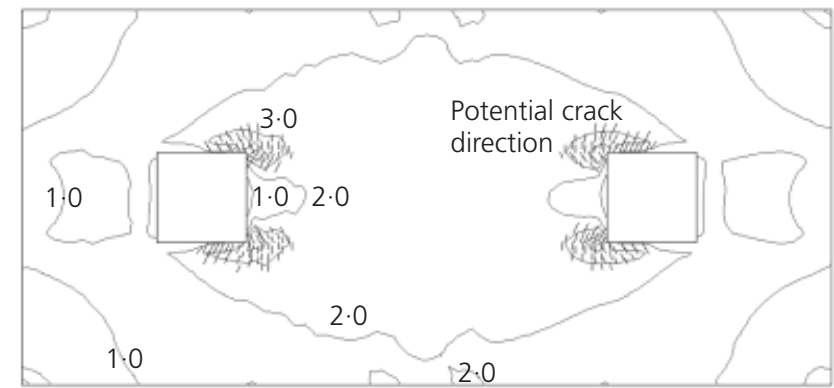

(b)

Figure 9. Major principal stress contour and potential cracks at $365 \mathrm{~d}$ : (a) as determined by conventional approach; (b) as determined by proposed approach. All values in $\mathrm{MPa}$

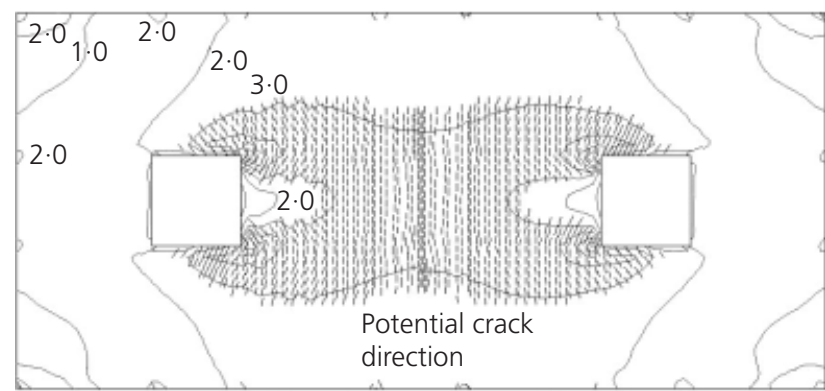

(a)

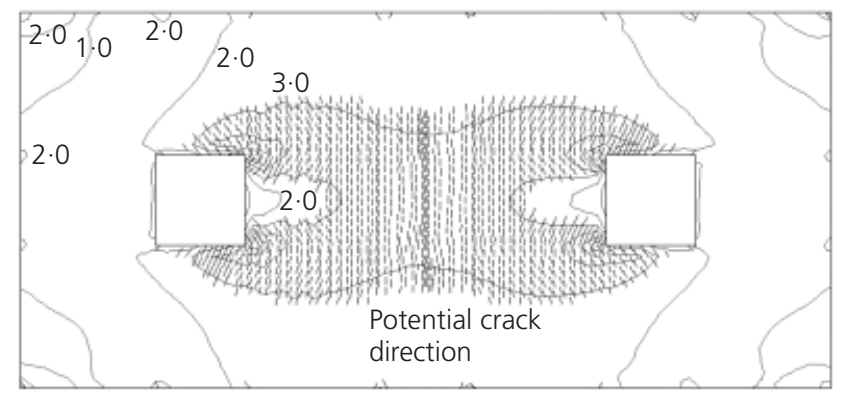

(b)

Figure 10. Major principal stress contour and potential cracks at $1095 \mathrm{~d}$ : (a) as determined by conventional approach; (b) as determined by proposed approach. All values in $\mathrm{MPa}$ 


\section{Conclusion}

The conventional approach of concrete creep analysis based on time-step integration requires memorisation of the stress histories of all the concrete elements. Such time-step integration demands a huge computer memory and a long computer time, especially when many time steps are used to trace the time-dependent strain and stress developments. To avoid having to memorise the stress histories and to deal with stress increments with undefined stress rates, a new numerical implementation of the multi-unit viscoelastic creep model based on remnant creep formulation, whereby the remnant creep strains are employed to evaluate the incremental creep strains at each time step and the incremental creep strains are evaluated in terms of stress increments rather than stress rates, has been developed.

The remnant creep formulation employs a multi-unit visco-elastic creep model, which allows the creep coefficient to be expressed in the form of a Dirichlet series. Step-by-step mathematical derivations of the remnant creep strains and the increment in creep strains at every time step have been presented. From the formulas so derived, it is seen that at any time step, the remnant creep strains can be obtained from the corresponding remnant creep strains at the immediate past time step and the increment in creep strains can be obtained from the current remnant creep strains. Hence, only updating of the remnant creep strains at each time step is needed and there is no longer any necessity to memorise the stress histories. As a result, the computational efficiency of the time-step analysis is dramatically improved.

The remnant creep formulation has been successfully applied to the prediction of concrete creep in accordance with the creep models given in CEB-FIP model code 1990 (and draft FIB model code 2010), ACI Committee 209 report, British Standard BS 5400: Part 4 and Eurocode 2: Part 2. Excellent agreement with the codified creep formulas has been achieved. Furthermore, numerical examples of time-dependent finite-element analysis of the shrinkage-induced stresses in a restrained concrete prism and a concrete podium structure are presented to demonstrate the applicability and accuracy of the new approach. It is advocated to adopt this approach in the analysis of time-dependent problems and the design of construction control measures.

\section{REFERENCES}

ACI (1992) ACI Committee 209: 209R-92: Prediction of creep, shrinkage, and temperature effects in concrete structures. American Concrete Institute, Farmintgon Hills, MI, USA.

Acker P and UIm FJ (2001) Creep and shrinkage of concrete: physical origins and practical measurements. Nuclear Engineering and Design 203(2-3): 143-158.

Alexander S (2002) Understanding shrinkage and its effects: part 1. Concrete 36(9): 61-63.

Anderson CA (1982) Numerical creep analysis of structures. In Creep and Shrinkage in Concrete Structures (Bazant ZP and Wittmann FH (eds)). Wiley, New York, NY, USA, pp. 259303.
Bazant ZP (1982) Mathematical models for creep and shrinkage of concrete. In Creep and Shrinkage in Concrete Structures (Bazant ZP and Wittmann FH (eds)). Wiley, New York, NY, USA, pp. 163-256.

Bazant ZP and Wu ST (1974) Rate-type creep law of aging concrete based on Maxwell chain. Materials and Structures 7(1): 45-60.

Beaudoin JJ, Tamtsia BT and Marchand J (2000) A reexamination of creep mechanisms in hydrated cement systems. Proceedings of the Materials Science of Concrete Workshop, Lake Shelbyville, IL, USA.

BSI (1990) BS 5400: Steel, concrete and composite bridges: Part 4: Code of practice for design of concrete bridges. BSI, London, UK.

CEB (Comité Euro-International du Béton) (1993) CEB-FIP model code 1990: Model code for concrete structures. Thomas Telford, London, UK.

CEN (Comité Européen de Normalisation) (2004) BS EN 1992: Eurocode 2: Design of concrete structures: Part 1-1: General rules and rules for buildings. BSI, London, UK.

CEN (2005) BS EN 1992: Eurocode 2: Design of concrete structures: Part 2: Concrete bridges - design and detailing rules. BSI, London, UK.

Creus GJ (1986) Viscoelasticity: Basic Theory and Applications to Concrete Structures. Springer, Berlin, Germany.

FIB (Fédération Internationale du Béton) (2012) FIB model code 2010: Final draft. FIB, Lausanne, Switzerland.

Ghali A, Favre R and Elbadry M (2012) Concrete Structures: Stresses and Deformations: Analysis and Design for Serviceability, 4th edn. Spon, London, UK.

Gilbert RI and Ranzi G (2011) Time-Dependent Behaviour of Concrete Structures. Spon, Abingdon, UK.

Guan H (2000) Construction Control of Cable-stayed Bridges. MPhil thesis, Department of Civil Engineering, The Hong Kong University of Science and Technology, Hong Kong.

Han DJ and Yan QS (2003) Chapter 7: Cable force adjustment and construction control. In Bridge Engineering. Construction and Maintenance (Chen WF and Duan L (eds)). CRC Press, Boca Raton, FL, USA.

Kim HS and Cho SH (2004) Shrinkage stress analysis of concrete slabs with shrinkage strips in a multistory building. Computers and Structures 82(15-16): 1143-1152.

Kim HS and Cho SH (2005) Shrinkage stress analysis of concrete slab in multistorey building considering variation of restraint and stress relaxation due to creep. The Structural Design of Tall and Special Buildings 14(1): 47-58.

Kwan AKH and Ng PL (2009) Shrinkage movement analysis of reinforced concrete floors constructed in stages. Computers and Concrete 6(2): 167-185.

Kwan AKH, Au FTK and Lee PKK (2002) Minimizing shrinkage cracks in concrete structures for better serviceability and durability. Proceedings of the Innovative Buildings Symposium, Hong Kong, pp. 117-136.

Kwan AKH, Au FTK and Lee PKK (2003) High-performance 
concrete buildings for the new millennium. Progress in Structural Engineering and Materials 5(4): 263-273.

McHenry D (1943) A new aspect of creep in concrete and its application to design. ASTM Proceedings 43: 1069-1084.

Neville AM (1955) Theories of creep in concrete. ACI Journal 52(9): 47-60.

Neville AM (1958) The influence of cement on creep of concrete and mortar. PCI Journal 2(1): 12-18.

Neville AM (2011) Properties of Concrete, 5th edn. Pearson Education, Harlow, UK.

Neville AM, Dilger WH and Brooks JJ (1983) Creep of Plain and Structural Concrete. Longman, Harlow, UK.

Ng PL, Lam JYK and Kwan AKH (2007) Multi-layer visco-elastic creep model for time-dependent analysis of concrete structures. In Proceedings of the Eleventh International Conference on Civil, Structural and Environmental
Engineering Computing, St. Julians, Malta, (Topping BHV (ed.)).

Powers TC (1968) Mechanisms of shrinkage and reversible creep of hardened Portland cement paste. Proceedings of an International Conference on the Structure of Concrete, London, UK, pp. 319-344.

Tamtsia BT and Beaudoin JJ (2000) Basic creep of hardened cement paste: a re-examination of the role of water. Cement and Concrete Research 30(9): 1465-1475.

Tamtsia BT, Beaudoin JJ and Marchand J (2004) The early age short-term creep of hardening cement paste: load-induced hydration effects. Cement and Concrete Composites 26(5): 481-489.

Vandamme M and Ulm FJ (2009) Nanogranular origin of concrete creep. Proceedings of the National Academy of Sciences 106(26): 10552-10557.

\section{WHAT DO YOU THINK?}

To discuss this paper, please email up to 500 words to the editor at journals@ice.org.uk. Your contribution will be forwarded to the author(s) for a reply and, if considered appropriate by the editorial panel, will be published as a discussion in a future issue of the journal.

Proceedings journals rely entirely on contributions sent in by civil engineering professionals, academics and students. Papers should be 2000-5000 words long (briefing papers should be 1000-2000 words long), with adequate illustrations and references. You can submit your paper online via www.icevirtuallibrary.com/content/journals, where you will also find detailed author guidelines. 